\title{
LXIV. On certain questions connected with astronomical physics
}

\section{S. Tolver Preston Ph.D.}

To cite this article: S. Tolver Preston Ph.D. (1906) LXIV. On certain questions connected with astronomical physics, Philosophical Magazine Series 6, 12:72, 570-576, DOI:

10.1080/14786440609463574

To link to this article: http://dx.doi.org/10.1080/14786440609463574

曲 Published online: 16 Apr 2009.

Submit your article to this journal $[\pi$

Џ Article views: 2

Q View related articles $\square$ 
LXIV. On Certain Questions connected with Astronomical Physics. By S. Tolver Preston, Ph.D.**

7 VHE Philosophical Magazine for March 1847 contains a paper under the title " The Form of the Earth no Proof of Original Fluidity," by Herbert Spencer. A remote date to any publication may tend to its being overlooked, and some of the conclusions in this article appear to be worthy of notice.

The implication of course is that in the case of our earth $\dagger$, gravitational pressure by itself alone would demonstrably suffice to have effected the compacted "flow" of solid substance into globular form, without the necessity for any preceding state of fluidity or of high temperature.

In the "flow of solids" (metals particularly) by the mere action of pressure, without any application of heat, subsequently demonstrated experimentally by Tresca, we may see a parallel effect actually produced and illustrative of the above theoretical view.

As a fact of general application, we may also notice that, provided the accumulation of aggregated material were assumed sufficiently gradual, or spread over an epoch of adequate duration, there might be time for any heat to dissipate; and so it appears there need be no real accumulation of heat from this cause, but rather a gradual yielding of materials under gravitational stress, somewhat comparable [say] to metals "flowing" under a very gradually augmented pressure. The sphere is then regarded as the natural $\ddagger$ form assumed under gravitation, even if there were no fluidity produced by heat.

But it would seem as if one fact had been overlooked by Herbert Spencer. For while, at the surface of the globe,

* Communicated by the Author.

+ Since our earth in the remote past is generally held to have rotated more quickly about its axis than now, any quantitative inference as to its shape, if grounded on the present rate of axial rotation, would appear to be open to question.

$\ddagger$ The pressure at the centre of our globe is calculated by Prof. T. J. J. See as equivalent to that of a column of mercury 2383.152 kilometres high-a pressure "so enormous that Prof. See attempts to render it more comprehensible by suggesting that it is 7838 times as great as that of a mercurial column equal in height to the Eiffel Tower" ('Nature,' March 2, 1905, p. 424). Curiotisly enough, this Tower is reputed to contain a mercurial manometer equal to its height [300 metres]. 
gravitational stress is insufficient to entail any such "welding" together of cold ingredients ; it is only at some depth below the surface [relatively insignificant, no doubt, compared with the diameter of the earth] that such crusbing effect could take action. Some minor irregularities of surface would thus be inferable from this condition (on our globe).

It may be worth noticing that recently in 'Nature' it was remarked that earthquake-waves, the velocity of which is now instrumentally measured, appear to indicate a rather abrupt change* of quality or density in the globe's interior, at a point about 30-40 miles from the surface. This consideration becomes of practical value in relation to possible additions to knowledge in connexion with earthquakes. Thirty miles thickness of crust, compared with the globe's diameter, is evidently but a thin shell.

Some of the observed internal heat of the earth's crust might be attributable to the chemical action of material of diverse nature, without necessarily appealing to an original nebulous condition. We must take all evidence and cooperative causesinto consideration, - every possible evolutionary process, slow, as well as catastrophic. The observed tide-resisting quality of our globe, whereby it has been inferred to resist distortion like glass or steel, - has, at any rate, to be harmoniously $\dagger$ accounted for. In 'Nature,' August 9, 1906, the following expression of view by Sir George Darwin is quoted :-

"On the whole, we may fairly conclude, whilst there is some evidence of a tidal yielding of the earth's mass, that yielding is certainly small, and the effective rigidity is at least as great as steel" (p. 358).

Demonstrably, there is much iron present in our universe, while this metal is known to be a chief constituent of meteorites (from actual analyses). Looking to a purpose to be fulfilled

* In an address at the recent meeting of the British Association by Principal E. H. Griffiths, attention is directed to a conclusion of Prof. Milne's, namely :-

"The difference in the rate of propagation of earthquake-waves through the earth's interior and through the crust, has led him [Prof. Milne] to the conclusion that the material below a depth approximating to thirty miles is of uniform nature, and that the change in physical constitution is abrupt at some such depth as that indicated " ("Nature,' August 9, 1906, p. 358).

$f$ On the other hand, it is a merely speculative idea, that pressure (extremely great) might at the temperature of fluidity solidify steel. It may be worth trying a much greater pressure than is applied in the instance of the "fluid compressed steel" of Whitworth, as a research experiment. 
by meteoritic bodies known to be scattered everywhere in stellar space (through which our system is moving as a whole at a speed estimated at four * miles per second) ; also in view of the meteoritic theory of cosmical evolution, coupled with the observed powerful magnetic qualities of our globe,-its more central portions may well be constituted of the metal iron. And certainly the fact that gravitation by itself alone would suffice to produce (withont the aid of heat) sphericity and the flow even of metals, would appear too interesting a point to neglect $\dagger$ altogether.

A metallic constitution for the chief bulk of our globe [the metal iron] would be quite consistent with the measured specific gravity of $5 \cdot 5$ : this being considerably greater than that of ordinary rocks. The keeping of alternative possibilities in view, so long as they be not inconsistent with recognized facts, may be an aid to progress and eventual demonstration.

In an address before the British Association at South Africa, chiefly on astronomical science, by Sir George Darwin, where the subject is popularly dealt with, is the following passage, which may be quoted in connexion with the foregoing :-

"The problems of cosmical evolution are so complicated that it is well to conduct the attack in various ways at the same time. Although the several theories may seem to some extent discordant with one another, yet, as I have already said, we ought not to scruple to carry each to its logical conclusion. We may be confident that in time the false will be eliminated from each theory; and when the true alone

* Few probably realize that for the sun (or solar system), with its estimated proper motion of four miles per second, to move a distance equal to that of a Centauri [parallax $=0^{\prime \prime} \cdot 93$ ], would demand but a small fraction of the life-history of the solar system, namely, 161,000 years (only). In the mean life of a system, average stellar distances in our universe would, it appears, be traversed some thousands of times. A diversity of physical conditions at diverse epochs may thus be presented to the speculative view, including possible gradual variation of the "temperature of space."

t At the sun's centre the pressure (according to the calculation of Prof. See) would be that of a mercury mumometer projecting beyond the sun's radius, with the quicksilver supposed subject everywhere to the value $g$ for acceleration at the earth's surface.

With such pressures as this, may not molecules (now recognized to consist of corpuscles) be, so to speak, "crushed out of shape" to some extent at least in the vicinity of the centre of the sun or of our globe, and so escape as "radioactive material"?

Is it likely that pressure without assigned limit can be sustained by minute configurations moving in orbits, withont entailing a radical disturbance of dynamical equilibiinn? 
remains the reconciliation of apparent disagreements will have become obvious." ("Nature,'August 31, 1905, p. 439.)

"To conduct the attack in various ways at the same time," being tantamount to "keeping of all alternative possibilities in view," may accordingly be a motive for inviting attention to some other aspects of the inquiry; while some extracts from Sir George Darwin's address appear to lend additional support to the view that planets may be formed by the accretion of meteoritic matter. First, by way of preface, be says :-

"The German astronomer Bode long ago propounded a simple empirical law concerning the distances at which the several planets move about the sun. It is true that the planet Neptune, discovered subsequentiy, was found to be considerably out of the place which would be assigned to it by Bode's law, yet, his formula embraces so large a number of cases with accuracy that we are compelled to believe that it arises in some manner from the primitive conditions of the planetary system.

"The explanation of the causes which have led to this simple law as to the planetary distances presents an interesting problem, and, although it is still unsolved, we may obtain some insight into its meaning by considering what $I$ have called a working model of ideal simplicity.

"Imagine then a sun round which there moves in a circle a single large planet. I will call this planet Jove, because it may be taken as a representative of our largest planet, Jupiter" ('Nature,' August 31, 1905, p. 439).

Next, a number of meteorites (some of which may be even comparable in size to asteroids) are supposed to be moving in all conceivable directions, so that certain of them fortuitously may enter the system composed of the sun and Jove. By mathematical analysis, it is found that there are certain "zones surrounding the sun and Jove in which stable orbits are possible, and others in which they are impossible. There is hardly room for doubt [it is added] that if a complete solution for our solar system were attainable, we should find that the orbits of the existing planets and satellites are numbered amongst the stable perpetual orbits, and should thus obtain a rigorous mechanical explanation of Bode's law concerning the planetary distances" (p. 439).

Previously it is remarked that while some of these meteoritic bodies "will be absorbed by the sun," a "minority will collide with Jove."

The process by which the meteorites,-which (it seems) must gradually accumulate more and more within the limits 
of the breadth of the zones-become eventual planets, is not entered upon. But the significance of the zones " in which stable orbits are possible" appears to be that only under this condition could meteoritic bodies coming from space accumulate [be virtually "selected"], constituting presumably material rings of discrete fragments of matter, somewhat reminding of the rings of Saturn *.

There is the difficulty, however, that a ring of material can only concentrate (aggregate) about its centre of gravity, which would imply its ultimately falling into the sun or central body.

But it might possibly be proposed that the mere fortuitous entry of meteorites (possessing a suitable "direction and speed ") into these zones, would, by the laws of probability, condition [round a given zone] an irregular distribution of material, rather than the reverse ; thus virtually constituting an ill-balanced or broken ring; which might then concentrate into a planet $\dagger$. And we have seen that, without the necessity for a preceding nebulous state, gravitation by itself can produce the compacted flow of even solid substavce into a natural globular (or rather oblate) form ; while internal heat for the inhabitability of a planet is of no use whatever.

Here seems a fit opportunity for inviting attention to the importance of according due weight in cosmology to Hutton and Lyell's principle or (rather) factor of slozo progressive changes, under a proper extension of time, coupled with natural causes at present observed to be in action, - which is acknowledged to have contributed so much to enlightenment in the allied science of geology. This slow natural process

* In reference to Saturn, Sir George Darwin remarks:- "The astonishing discovery has just been made by William Pickering of a ninth retrograde satellite of Saturn, while the rotations of the eight other satellites, of the ring, and of the planet itself, are direct." (Address, p. 440, in 'Nature').

But in that same Journal (only 27th of April previously-same year), is a letter by Prof. William J. Pickering (p. 608), where he expresses rather the reverse of surprise at this retrograde motion of the satellite discovered by him, and proposes to harmonize its motion with a fundamental property of gyrustatic motion, which, since his letter bears the title-"A little known Property of the Gyroscope," Prof. Pickering wonld seem to consider has escaped an adequate appreciation.

t. It may be just worth a passing notice that in a so-called "meteoritic plenum," the components of any "double" (forming after the manner described in the moon's evolution) would differentiate in mass, after separation or severance, on account of more meteorites falling continually into the greater or central body. Thus it might seem that the mass (say of a "large planet") which was judged too small relatively to the primary for this particular evolutionary process to be applicable, might have been more equal to the primary at the very remote epoch when th1s "double" originated (or could have originated). 
may well cooperate or even rival in fundamental import the more catastrophic processes exemplified by the nebular theory of Kant and Laplace, which [contrasted with the slow procedure] involve an intense development of heat, with liquefaction or vaporization of materials.

If we leave provisionally out of view the primordial constituents of matter, namely the "corpuscles" recognized to belong to the domain of "Radioactivity": then, for the building of systems, the only available substance appears to be the substance of meteoritic bodies, whichawe can actually handie and analyse in the laboratory. If it be conceded that, by a natural process, systems cannot evolve out of nothing, the visualizing of a purpose to be fulfilled by this everywhere present meteoritic matter becomes of logical fitness; and it appears that no evolutionary theory of cosmical systems becomes satisfactory, unless it recognizes this universal substance as a fundamental constituent (or basis), whether the procedure concerned in any given case be regarded as slow, spread over an extensive time-epoch, with unimportant accumulation of heat; or as catastrophic, as in the instance of the nebular theory, where it appears that in the first stage the nebula itself " may be regarded as a quasi gas, the molecules of which are meteorites."

In our system, consider the numerous asteroids*. It seems to be often tacitly supposed or taken for granted that these bodies in their movement of circulation about the sun were once fluid or luminous, that they represent minor planets which have cooled down. But they might never have been incandescent or even have possessed a temperature worth mentioning; but may have been formed by the slow and gradual accretion $\dagger$ of meteoritic bodies into that spherical

* It appears a remarkable fact that the meteorites composing the ring of Saturn circulate all substantially in one plane; whereas this is not the case with the asteroids, the orbits of which deviate considerably from a plane. This would appear to indicate a mode of evolution not quite the same in the two cases. Any suggestion, based on recognized causes, as to the mode of origin of the asteroidal ring, seems preferable to the theory of an "exploded planet," the fragments of which are to represent the asteroids.

+ There may be no objection to my quoting here a passage from a letter received on April 9, 1893, from Sir George Darwin, as it bears on the present subject :-

"I cannot help feeling that Newcomb is wrong to throw over Bode's law. It is wrong perhaps to call it a law, but for my part I believe that the sequence of mean distances observed in the planets is due to physical relationship amongst their perturbing powers on one another. I think that sometime it will be discovered what that relationship is, and then that it will appear that some term which remains negligible in the interior planets has risen to importance when we get to Neptune so as to disturb his times." 
shape which gravity by itself ean condition ; but the intensity of which being less in consideration of the smaller bulk of the asteroids, might entail [if this were the sole cause of accretion $\rfloor$ an internal structure less closely packed than in the instance of our earth*. It appears, however, that whatever the existing structure of the asteroids, this structure must at least be able to hold together against the existent value of tidal action on these bodies.

September 2, 1900.

LXV. Simultaneous Villation-Curves of String and Air photographically oltained from a Monochord. By Prof. E. H. Barton, D.Sc., F.R.S.E., and J. Penzer $\dagger$.

\section{[Plate XIX.]}

COME time ago it appenred to one of us desirable to $\$$ investigate the relations between the vibrations of a string and those which consequently oceur in the bridge, sound-box, and contained air of the instrument on which the string is mounted. In 1905 the first instalment $\ddagger$ of this work appeared and dealt with the motion of the belly and the string of a monochord when bowed. The present paper forms the second contribution to the entire problem, and is concerned with the string and air in the sound-box of the same monochord, both bowing and plucking being used in contrast.

\section{Experimental Arrangements.}

The string's motion is here recorded by the same method as in the former paper, and is shown in the positive prints or their reproductions by a black line on a white ground, the focussed shadow of the string rising and falling periodically on the lower portion of the photographic plate, as the plate itself shoots uniformly along the horizontal.

The motion of the air in and out of the sound-box was

* In 'Science Abstracts' (August 25, 1906, p. 394) is a communication headed "Flow of Concrete under Pressure," abstracted from 'Eng. News, Nov. 2, 1905, in which an experiment by I. H. Woolson is described, where a tube of steel containing set concrete (four inches in diameter) widened to a diameter of five inches under pressurs applied to the concrete. It is added that, "On sawing the tube, the concrete is found to have 'flowed' like a plastic material and to have taken the exact shape of the distorted tube. Reference is made to F. D. Adams, who has shown that marble will flow in this way." (Amer. Geological Soe. 1901.)

+ Communicated by the Autiors.

† Barton \& Garrett, Phil. Mag. July 1905, pp. 149-157. 